\title{
Effects of corticosteroids in patients with sickle cell disease and acute complications: a systematic review and meta-analysis
}

\author{
Julien Lopinto,,$^{1,2}$ Ségolène Gendreau, ${ }^{1,2^{\star}}$ Enora Berti, ${ }^{1,2}$ Pablo Bartolucci, ${ }^{3,4}$ Anoosha Habibi ${ }^{3,4}$ \\ and Armand Mekontso Dessap 1,2,3

\begin{abstract}
'AP-HP, Hôpitaux Universitaires Henri-Mondor, Service de Médecine Intensive Réanimation, Créteil; ${ }^{2}$ Université Paris Est Créteil, CARMAS; ${ }^{3}$ Université Paris Est Créteil, INSERM, IMRB, FHU SENEC and ${ }^{4}$ Université Paris Est Créteil, Centre de Référence des Syndromes Drépanocytaires Majeurs, Unité des Maladies Génétiques du Globule Rouge (UMGGR), Créteil, France
\end{abstract}

*JL and SG contributed equally as co-first authors.

\author{
Correspondence: \\ Julien Lopinto \\ julien.lopinto@aphp.fr \\ Received: $\quad$ September 28, 2021. \\ Accepted: January 4, 2022. \\ Prepublished: January 13, 2022. \\ https://doi.org/10.3324/haematol.2021.280105 \\ ○2022 Ferrata Storti Foundation \\ Haematologica material is published under \\ a CC-BY-NC license (c) 8 (1) $\Theta$
}

\begin{abstract}
Whether corticosteroids improve outcome in patients with acute complications of sickle cell disease (SCD) is still debated. We performed a systematic review of the literature with the aim of estimating effects of corticosteroids on the clinical course of vaso-occlusive crisis (VOC) or acute chest syndrome (ACS) in patients with SCD. The primary outcome was transfusion requirement during hospitalization. Studies were identified by search of MEDLINE and CENTRAL database. Three randomized clinical trials (RCT) and three retrospective cohort studies (RCS) were included, involving 3,304 participants and 5,562 VOC or ACS episodes. There was no difference between corticosteroids and standard treatment regarding transfusion requirement overall (odds ratio $[\mathrm{OR}]=0.98,95 \%$ confidence interval $[\mathrm{Cl}]$ : 0.38-2.53) but there was a significant interaction of the study type $(P<0.0001)$ : corticosteroid therapy was associated with a lower risk of transfusion in RCT $(\mathrm{OR}=0.13,95 \% \mathrm{Cl}: 0.04-0.45)$ and a higher risk of transfusion in RCS (OR=2.12, 95\% Cl: 1.33-3.40. In RCT, the length of hospital stay was lower with corticosteroids as compared with standard treatment: mean difference -24 hours (95\% Cl: -35 to -14). Corticosteroids were associated with an increased risk of hospital readmission as compared with standard treatment, in RCT, RCS, and the entire cohort: OR=5.91, 95\% Cl: 1.40-24.83; OR=3.28, 95\% Cl: $1.46-7.36$ and OR=3.21, 95\% $\mathrm{Cl}: 1.97-5.24$, respectively. Corticosteroids were associated with reduced number of transfusions and length of stay in RCT but not in RCS, with more rehospitalizations overall. Additional RCT should be conducted while minimizing the risk of rehospitalizations.
\end{abstract}

\section{Introduction}

Sickle cell disease (SCD) is one of the most common monogenic disorders in the world. Acute painful episodes (vaso-occlusive crisis, VOC) and acute chest syndrome (ACS) represent the two most common acute events of this disease. Indeed, VOC is the primary cause of emergency department admissions and hospitalization ${ }^{1}$ while ACS is the main cause of death in adults. ${ }^{2,3}$ Erythrocyte abnormalities in SCD lead to microvascular occlusion and intravascular hemolysis, producing free hemoglobin and resulting in ischemia-reperfusion organ injury and infarction. These vaso-occlusive events promote inflammation and expression of adhesion receptor on endothelium cells. ${ }^{4,5}$
Corticosteroids reduce inflammation, by inhibiting cytokines and endothelial cell activation, reducing expression of P-selectin and vascular cell adhesion molecule-1 on endothelium. ${ }^{5-7}$ These effects could be useful to mitigate VOC and/or ACS, considering the potential benefit of inhibiting inflammatory response and intravascular hemolysis. Whether corticosteroids improve outcome (e.g., transfusion requirement or hospital length of stay) in patients with VOC or ACS is still debated. Many SCD specialists discourage the use of corticosteroids and report potential severe adverse events following corticosteroids therapy. Using a systematic review including a metaanalysis of randomized clinical trials (RCT) and retrospective cohort studies (RCS) may provide an accurate estimation of the potential benefits of corticosteroids in 
the course of acute complications in patients with SCD. The main objective of this study was to review the literature and provide a meta-analysis on the effects of corticosteroids on the clinical course of VOC or ACS in children and adults with SCD.

\section{Methods}

\section{Search strategy and selection criteria}

This systematic review was performed according to the PRISMA (Preferred Reporting Items for Systematic reviews and Meta-Analysis) guidelines. ${ }^{8}$ We searched CENTRAL and MEDLINE, from inception to 04/28/2021 using the search items "sickle cell disease," "acute chest syndrome," "vasoocclusive crisis," "steroids," "corticosteroids," "methylprednisolone," "prednisone," "dexamethasone," "prednisolone."

\section{Type of studies, participants and outcomes}

We restricted our research to RCT and RCS comparing the effects of systemic corticosteroids with standard treatment. Inclusion criteria were as follows: population of children or adults, hospitalized for VOC or ACS, intervention involving systemic corticosteroids therapy during hospitalization (prednisone, methylprednisolone, prednisolone or dexamethasone). Exclusion criteria included the following: studies without a control group, studies assessing inhaled or topical corticosteroids therapy, comments and studies not written in English. The primary outcome of the review was transfusion requirement during hospitalization. References of all selected articles were scanned for additional relevant manuscripts. Ethical approval was not required.

\section{Data extraction}

See the Online Supplementary Appendix.

\section{Assessment of risk of bias (quality assessment)}

Two authors (JL, SG) independently assessed the study method quality by using the RoB 2.0 tool released through the Cochrane, to assess risk of bias in randomized studies. ${ }^{9,10}$ In non-randomized trials, we assessed the risk of bias using the ROBINS-I tool released through the Cochrane. ${ }^{11}$ In case of disagreement, a third researcher (AMD) adjudicated the assessment of risk of bias. The risk of bias was assessed according to preliminary considerations, the randomization process, effect of assignment to intervention, effect of starting and adhering to intervention, missing outcome data, and selection of the reported result. Data were presented using the robvis $\mathrm{R}$ package. ${ }^{12}$

\section{Data analysis}

We estimated the effective sample size for each study based on their respective design effect. Data were sum- marized using medians and interquartile ranges (IQR) or mean (standard deviation, SD) where appropriate. ${ }^{13}$ We adopted the inverse variance method for developing weights for individual study effects. We quantified heterogeneity using $\mathrm{I}^{2}$ and $\mathrm{Q}$ statistics, with values greater than $50 \%$ regarded as being indicative of moderate-to-high heterogeneity. ${ }^{14}$ We used a random effect model to assess the population average mean difference and $95 \%$ IC of intervention. We did subgroup analyses of the type of trial included (RCT or RCS) and a sensitivity analysis focusing on ACS. Treatment effects in subgroups were compared by a test of interaction (using Cochran's Q test and Higgins' $\left.1^{2}\right) . .^{15}$ In order to evaluate an outcome, we needed at least three studies that analyzed it with complete data. Individual study effects and pooled effects were visualized through forest plots. Publication biases were assessed graphically through traffic-light plot. Data were pooled using Review manager with a 2 -sided significance of $5 \%$.

\section{Study registration}

This study was submitted to the International Prospective Register of Systematic Reviews (PROSPERO) database (clinicaltrials gov. Identifier: CRD42021265528).

\section{Results}

\section{Selection of studies}

We identified 2,577 references from our searches (Figure 1). After removing 1,112 duplicates, we screened 1,465 titles of whom 1,437 were excluded. We then screened 28 abstracts, among which we identified nine potentially eligible articles. Among the 19 studies excluded by abstract, there were seven systematic reviews not eligible for analysis because they did not provide original data and/or did not address the question of systemic corticosteroids therapy in the field of VOC and/or ACS.

Full texts of nine studies were reviewed and three were excluded because of the absence of a control group $(n=2)^{16,17}$ or absence of comparative analysis between corticosteroids and a control group $(n=1) .{ }^{18}$ Finally, six studies were included in the meta-analysis, involving 3,304 participants and 5,562 VOC or ACS episodes.

\section{Clinical definitions}

VOC was defined as pain or tenderness affecting at least one part of the body, requiring opioids, and not explained by other causes. ${ }^{19}$ ACS was defined as an acute illness with fever and/or respiratory symptoms, accompanied by a new pulmonary infiltrate on chest X-ray. ${ }^{20-24}$ Severe ACS was defined by the need for intensive care unit admission, ${ }^{24}$ or the presence of one of the following severity signs, involving the neurologic system (e.g., lethargy) or the respiratory system (e.g., extensive pulmonary infiltrates [bilateral, one 


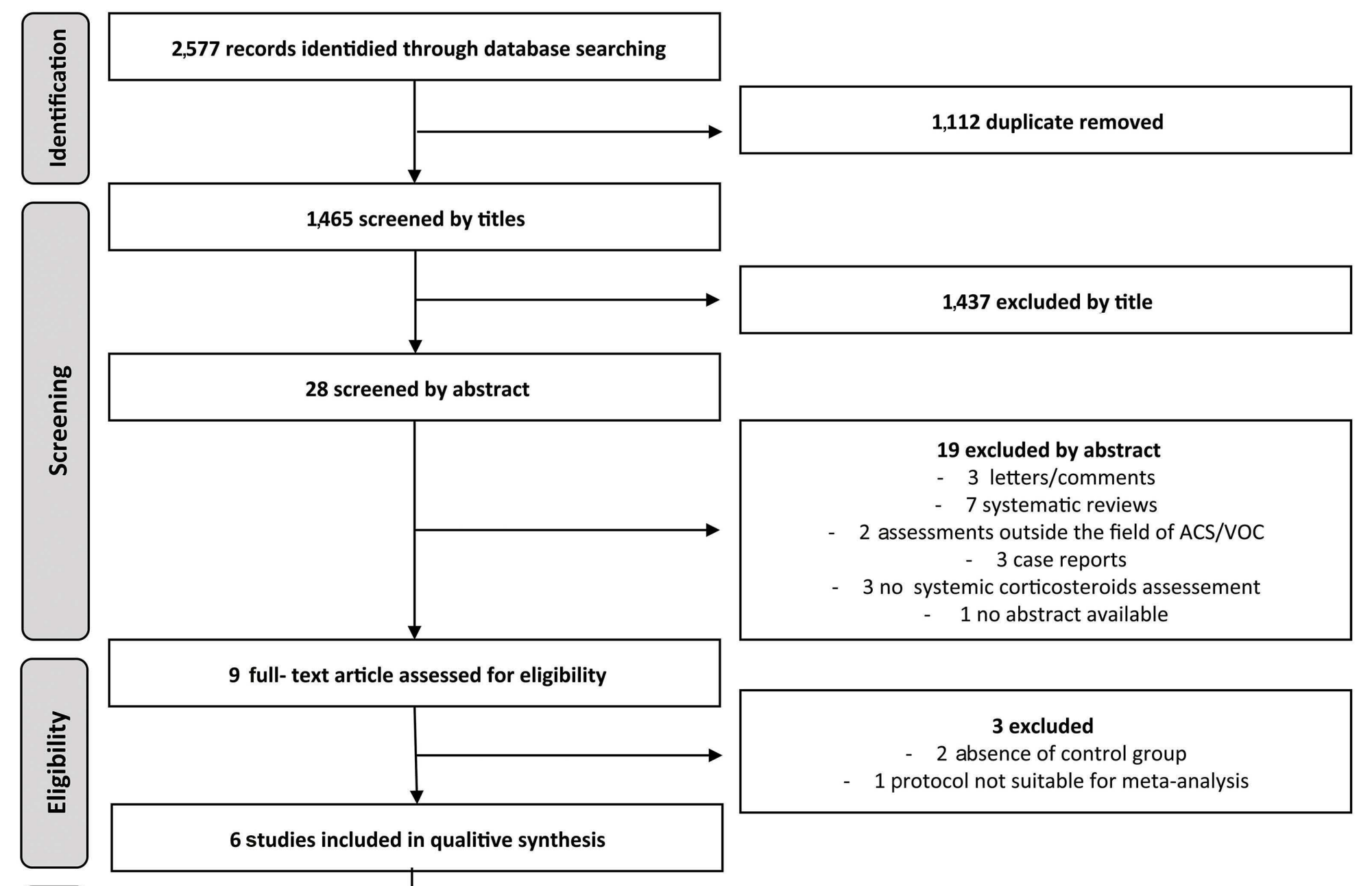

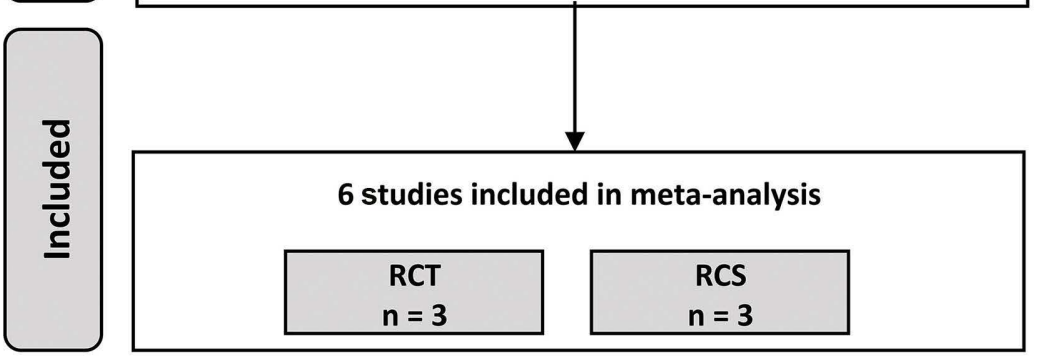

complete lung or three lobes], marked arterial hypoxemia [transcutaneous oxygen saturation $\left(\mathrm{SpO}_{2}\right)<85-90 \%$ despite supplemental oxygen, tachypnea and $\mathrm{SpO}_{2}<95 \%$ in room air], need for invasive or non-invasive respiratory support). ${ }^{20-23}$

\section{Study design}

Among the included studies, three were $\mathrm{RCT}^{19-21}$ and three were $\mathrm{RCS}^{22-24}$. Studies were held in United State of America; they were multi-center $(n=3)^{21,23,24}$ or took place in a single-center of a department of pediatric hematology $(n=3)^{19,20,22}$. Studies evaluated mostly the pediatric population ( $n=5) ;^{19,20,22-24}$ one assessed both the adult and pediatric population. ${ }^{21}$ All studies reported corticosteroids impact in the field of ACS $(n=5)^{20-24}$ or VOC $(n=1)^{19}$ (Table 1).

In the three RCT, corticosteroid therapy was evaluated versus placebo in a controlled double-blinded fashion; corticosteroids and placebo groups were comparable in terms of demographics, clinical and biological characteristics at baseline..$^{19-21}$ On the contrary, in each of the three RCS included, several baseline clinical characteristics were significantly different between patients receiving steroids and their counterparts. There was no severe ACS included in RCT, while the rate of severe ACS in RCS was higher in patients receiving steroids as compared with their counterparts (Online Supplementary Table S1).

\section{Quality}

Included studies differed in their methodological quality (Online Supplementary Figures S1). High risk of bias was related to confounding factors and classification of interventions in the RCS. ${ }^{22-24}$

\section{Intervention}

All studies compared corticosteroids with a control group of standard of care. Standard of care was comparable among all studies and was in accordance with current guidelines: ${ }^{25}$ bed rest, supplemental oxygen, intravenous hydration, folate supplementation, analgesics and blood products transfusion, as needed..$^{19-24}$

The intervention protocols were heterogeneous regarding corticosteroids class, dosing and duration of therapy (Table 2). Corticosteroid therapy consisted of dexamethasone $(n=2),{ }^{20,21}$ methylprednisolone $(n=1),{ }^{19}$ prednisone $(n=1)^{23}$ or several classes of corticosteroids (including dexamethasone, prednisone, prednisolone and methylprednisolone) $(n=2) .{ }^{22,24}$ Duration of corticosteroid therapy 
Table 1. Characteristics of included trials.

\begin{tabular}{|c|c|c|c|c|c|c|}
\hline Trial, year & Griffin, $1994^{19}$ & Bernini, $1998^{20}$ & Strouse, $2008^{22}$ & Sobota, $2009^{24}$ & Kumar, $2010^{23}$ & Quinn, 201121 \\
\hline $\begin{array}{l}\text { Inclusion } \\
\text { criteria }\end{array}$ & Vaso-occlusive crises & $\begin{array}{l}\text { Moderate acute } \\
\text { chest syndrome }\end{array}$ & $\begin{array}{l}\text { Acute chest } \\
\text { syndrome }\end{array}$ & $\begin{array}{l}\text { Acute chest } \\
\text { syndrome }\end{array}$ & $\begin{array}{l}\text { Acute chest } \\
\text { syndrome }\end{array}$ & $\begin{array}{l}\text { Acute chest } \\
\text { syndrome }\end{array}$ \\
\hline $\begin{array}{l}\text { Type of } \\
\text { study }\end{array}$ & $\begin{array}{c}\text { Randomized } \\
\text { controlled double-blind } \\
\text { protocol }\end{array}$ & $\begin{array}{l}\text { Randomized } \\
\text { controlled double- } \\
\text { blind protocol }\end{array}$ & $\begin{array}{l}\text { Retrospective } \\
\text { cohort }\end{array}$ & $\begin{array}{l}\text { Retrospective } \\
\text { cohort }\end{array}$ & $\begin{array}{l}\text { Retrospective } \\
\text { cohort }\end{array}$ & $\begin{array}{l}\text { Randomized } \\
\text { controlled double- } \\
\text { blind protocol }\end{array}$ \\
\hline $\begin{array}{l}\text { Recruitment } \\
\text { period }\end{array}$ & $1990-1991$ & $1992-1995$ & $1998-2004$ & 2004-2008 & $2005-2007$ & 2006-2008 \\
\hline $\begin{array}{l}\text { Participants } \\
\text { (number of } \\
\text { episodes) }\end{array}$ & $36(56)$ & $38(43)$ & 65 (126) & $3,090(5,247)$ & $63(78)$ & $12(12)$ \\
\hline $\begin{array}{l}\text { Primary } \\
\text { outcome }\end{array}$ & $\begin{array}{c}\text { Doses of intravenous- } \\
\text { morphine } \\
\text { Continuous intra- } \\
\text { venous morphine } \\
\text { Duration of analgesia, } \\
\text { Clinical complications }\end{array}$ & $\begin{array}{l}\text { Length of hospital } \\
\text { stay }\end{array}$ & $\begin{array}{l}\text { Readmission rate } \\
\text { Length of hospital } \\
\text { stay }\end{array}$ & $\begin{array}{c}\text { Length of hospital } \\
\text { stay } \\
\text { Readmission rate }\end{array}$ & $\begin{array}{l}\text { Readmission } \\
\text { rate }\end{array}$ & $\begin{array}{l}\text { Duration of } \\
\text { acute chest } \\
\text { syndome }\end{array}$ \\
\hline
\end{tabular}

d: day.

Table 2. Characteristics of corticosteroid protocol in included studies.

\begin{tabular}{|c|c|c|c|c|c|c|}
\hline Study, year & Griffin, $1994^{19}$ & Bernini, $1998^{20}$ & Strouse, $2008^{22}$ & Sobota, $2009^{24}$ & Kumar, $2010^{23}$ & Quinn, 201121 \\
\hline $\begin{array}{l}\text { Corticosteroid } \\
\text { class (dose) }\end{array}$ & $\begin{array}{c}\text { Methyl- } \\
\text { prednisolone } \\
(15 \mathrm{mg} / \mathrm{kg} / \mathrm{d})\end{array}$ & $\begin{array}{l}\text { Dexamethasone } \\
(0.6 \mathrm{mg} / \mathrm{kg} / \mathrm{d})\end{array}$ & $\begin{array}{c}\text { Dexamethasone } \\
(0.6 \mathrm{mg} / \mathrm{kg} / \mathrm{d}) \\
\text { or } \\
\text { Prednisone } \\
\text { (1 to } 2 \mathrm{mg} / \mathrm{kg} / \mathrm{d}) \\
\text { or } \\
\text { Prednisolone } \\
(2 \mathrm{mg} / \mathrm{kg} / \mathrm{d})\end{array}$ & $\begin{array}{c}\text { Dexamethasone } \\
\text { (NI) } \\
\text { or } \\
\text { Prednisone (NI) } \\
\text { or } \\
\text { Prednisolone (NI) } \\
\text { or } \\
\begin{array}{c}\text { Methylprednisolone } \\
\text { (NI) }\end{array}\end{array}$ & $\begin{array}{l}\text { Prednisone } \\
(2 \mathrm{mg} / \mathrm{kg} / \mathrm{d})\end{array}$ & $\begin{array}{c}\text { Dexamethasone } \\
(0.6 \mathrm{mg} / \mathrm{kg} / \mathrm{d})\end{array}$ \\
\hline $\begin{array}{l}\text { Equivalent dose } \\
\text { of Prednisone, } \\
\mathrm{mg} / \mathrm{kg} / \mathrm{d}\end{array}$ & 18.75 & 4 & 1 to 4 & $\mathrm{NI}$ & 2 & 4 \\
\hline $\begin{array}{l}\text { Treatment } \\
\text { duration, days }\end{array}$ & 2 & 2 & 1 to 6 & $\mathrm{NI}$ & 5 & 8 \\
\hline
\end{tabular}

NI: no information; d: day.

varied from 1 to 8 days. Details on the intervention protocol was not available in one study. ${ }^{24}$

\section{Outcomes}

Variables reported for each study as primary outcomes included hospital readmission rate $(n=1),{ }^{23}$ length of hospital stay $(n=1),{ }^{20}$ duration of ACS $(n=1)^{21}$ and composite outcomes $(n=3)^{19,22,24}$ (Table 1). Outcome data were completely available for transfusion requirement $(n=6)$, and readmission rate $\left(72\right.$ hours, $n=2^{20,24}$ or 2 weeks, $n=4^{19,21-23}$ after hospital discharge), but not for length of hospital stay $(n=3) \cdot{ }^{19-21}$ Data on volumes transfused and mortality were never reported in included studies. We could not evaluate other outcomes (opioids doses and duration of analgesic therapy, incidence rate and duration of oxygen therapy, delay for hospital readmission) because less than three studies reported each of these outcomes with complete data.

\section{Effect of intervention}

Transfusion requirement (Figure 2)

In the subgroup of RCT, corticosteroid therapy was associated with a lower risk of transfusion as compared with standard treatment: OR=0.13 (95\% Cl: 0.04-0.45; 
$\left.\mathrm{I}^{2}=0 \%\right) .{ }^{19-21}$ On the contrary, in the subgroup of RCS, corticosteroids therapy was associated with a higher risk of transfusion: OR=2.12 (95\% Cl: $\left.1.33-3.40 ; I^{2}=33 \%\right) .{ }^{22-24}$ When we pooled all included trials, there was no difference between corticosteroid therapy and standard treatment regarding transfusion: OR=0.98 $(95 \% \mathrm{Cl} 0.38-$ $\left.2.53 ; 1^{2}=75 \%\right) .{ }^{19-24}$ We found a significant interaction between the type of study (RCT or RCS) and the risk of transfusion (Cochran's $Q$ test: $\chi^{2}=17.10$, df $=1, P<0.0001$, Higgins's $\left.\right|^{2}=94.2 \%$, Figure 2).

\section{Length of hospital stay (Figure 3)}

In the three RCT with available data, the length of hospital stay was lower with corticosteroids as compared with standard treatment: mean difference - 24 hours (95\% Cl: -35 to $\left.-14 ; I^{2}=0 \%\right) \cdot{ }^{19-21}$

\section{Hospital readmission (Figure 4)}

Corticosteroids therapy was associated with a significantly increased risk of hospital readmission as compared with standard treatment, in RCT, RCS, and the entire cohort: OR=5.91 (95\% Cl: 1.40-24.83; $\left.\left.\right|^{2}=0 \%\right)^{19-21} ;$ OR=3.28 (95\% Cl: $1.46-$ 7.36; $\left.\left.\right|^{2}=56 \%\right)^{22-24}$; and 3.21 (95\% Cl: $\left.1.97-5.24,\left.\right|^{2}=13 \%\right)^{19-24}$, re- spectively. Tests of interaction between the study type (RCT or RCS) and the effect on hospital readmission did not evidence a significant interaction between subgroups (Cochran's $Q$ test: $\chi^{2}=0.49, d f=1, P=0.48$, Higgins's $I^{2}=0 \%$, Figure $4)$. The main reason for readmission was painful crisis recurrence (Online Supplementary Table S2).

\section{Sensitivity analysis}

A sensitivity analysis was performed including only studies on ACS. ${ }^{20-24}$ Results were similar to those observed in the main analysis (Online Supplementary Figure S2; Online Supplementary Table S3). We also performed a sensitivity analysis including only the pediatric population..$^{19,20,22-24}$ The results were also similar to those observed in the main analysis (Online Supplementary Figure S3; Online Supplementary Table S4).

\section{Discussion}

Several systematic reviews have been published over the past years in the field of SCD to assess analgesic intervention $^{26-28}$ or transfusion therapy efficacy ${ }^{29}$ in the setting of

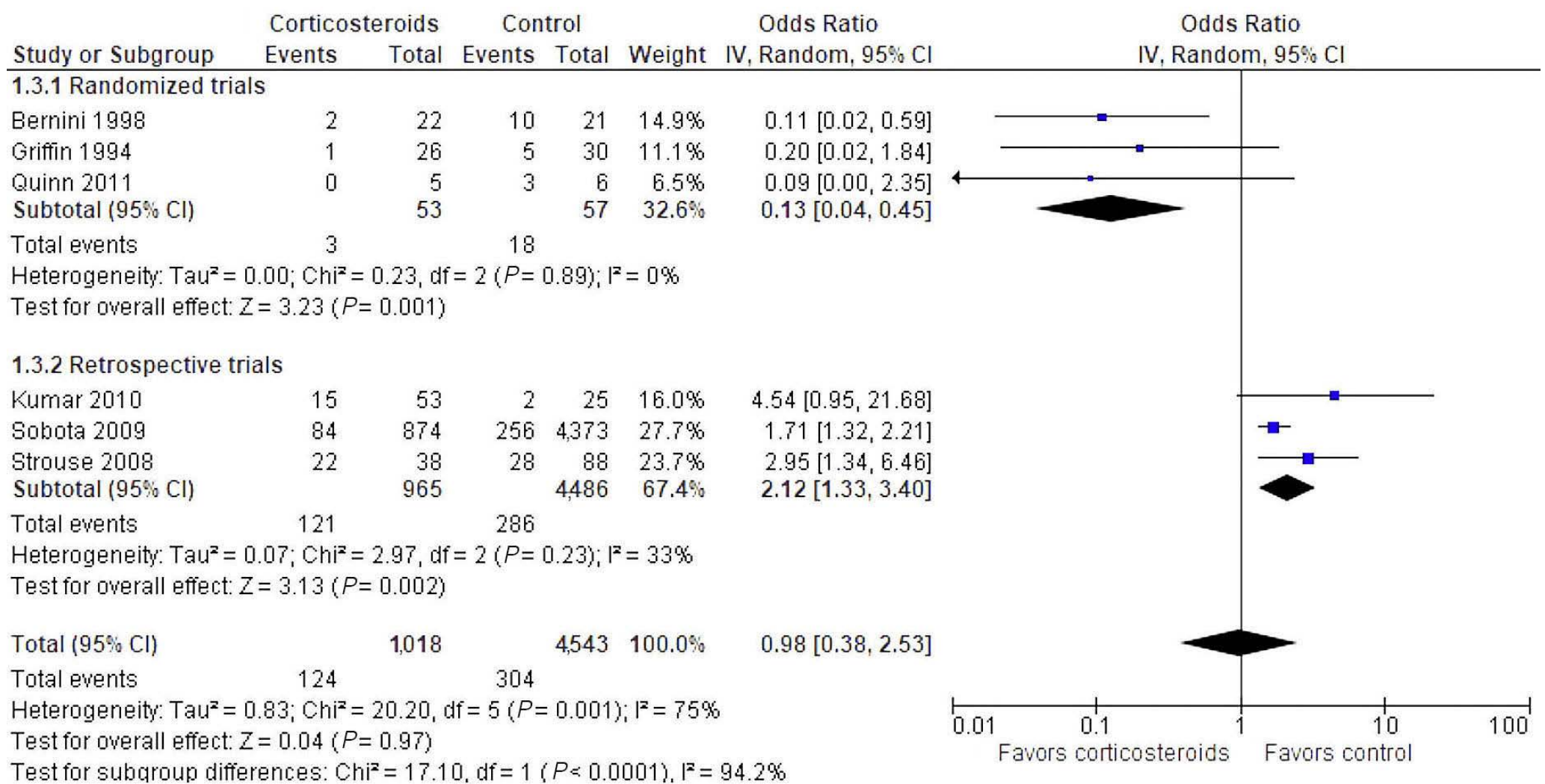

Figure 2. Effect of corticosteroids on transfusion requirement. $\mathrm{Cl}$ : confidence interval.

\begin{tabular}{|c|c|c|c|c|c|c|c|c|c|c|c|c|}
\hline \multirow[b]{2}{*}{ Study or Subgroup } & \multicolumn{3}{|c|}{ Corticosteroids } & \multicolumn{2}{|c|}{ Control } & \multirow[b]{2}{*}{ Total } & \multirow[b]{2}{*}{ Weight } & \multirow{2}{*}{$\begin{array}{c}\text { Mean Difference } \\
\text { IV, Random, } 95 \% \mathrm{Cl}\end{array}$} & \multirow{2}{*}{\multicolumn{4}{|c|}{$\begin{array}{c}\text { Mean Difference } \\
\text { IV, Random, } 95 \% \mathrm{Cl}\end{array}$}} \\
\hline & Mean & SD & Total & Mean & SD & & & & & & & \\
\hline Bernini 1998 & 47 & 16 & 22 & 80 & 50 & 21 & $23.4 \%$ & $-33.00[-55.41,-10.59]$ & & $\longrightarrow$ & & \\
\hline Griffin 1994 & 92 & 45 & 26 & 122 & 65 & 30 & $14.0 \%$ & $-30.00[-58.99,-1.01]$ & & & & \\
\hline Quinn 2011 & 42 & 9 & 5 & 62 & 14 & 6 & $62.6 \%$ & $-20.00[-33.70,-6.30]$ & & & & \\
\hline Total $(95 \% \mathrm{Cl})$ & & & 53 & & & 57 & $100.0 \%$ & $-24.44[-35.28,-13.60]$ & & & & \\
\hline $\begin{array}{l}\text { Heterogeneity: Tau } \\
\text { Test for overall effect }\end{array}$ & $\begin{array}{l}0.00 ; \mathrm{Cl} \\
\mathrm{Z}=4.42\end{array}$ & $\begin{array}{l}=1.1 \\
0<0 .\end{array}$ & $\begin{array}{l}\text { 1, } d f= \\
00001)\end{array}$ & $2(P=0$ & $58) ;$ & $F^{2}=0 \%$ & & & -100 & $\begin{array}{l}-50 \\
\text { corticosteroids }\end{array}$ & $\begin{array}{cc}0 & 50 \\
& \text { Favors control }\end{array}$ & 100 \\
\hline
\end{tabular}

Figure 3. Effect of corticosteroid therapy on the length of hospital stay. SD: standard devaition; CI: confidence interval. 
VOC or ACS. Two recent studies reported a descriptive review, assessing available evidence in favor and against the use of corticosteroids therapy, but without metaanalysis. ${ }^{30,31}$ Our work is, to the best of our knowledge, the first meta-analysis on the impact of corticosteroids on the clinical course of acute complications in patients with SCD. The use of corticosteroids was associated with i) a decrease in the need for transfusion in RCT, but not in RCS, with a significant interaction between the outcome and the type of study and ii) an increase in hospital readmission rates both in RCT and RCS.

\section{Conflicting effects on transfusion requirement}

Our analysis on transfusion requirement reported conflicting results between RCT and RCS. Indeed, it appears that corticosteroids reduce transfusion requirement in RCT whereas they were associated with more transfusion requirement in RCS, with a significant interaction between the outcome and study subgroups. One hypothesis for this discrepancy could be the absence of comparable groups in retrospective cohorts. Indeed, differences in baseline severity are potential confounders in RCS (Online Supplementary Table S1). Thus, results from retrospective cohorts could reflect the worse baseline severity of patients having received corticosteroids therapy (inasmuch as exchange transfusion is recommended in case of VOC or ACS with severity criteria in some guidelines ${ }^{25}$ ). Another hypothesis about conflicting results between RCT and RCS could be the timing between corticosteroids and transfusion: whereas steroids where administered before transfusion in RCT, they were given after transfusion in some patients in RCS. ${ }^{22}$ The association between steroid use and increased transfusion requirement in RCS should be interpreted with caution and may reflect the rescue use of steroids in more severe patients. By contrast, the subgroup analysis of the three RCT showed a significant reduction of transfusion requirement in the corticosteroids group. This result is in accordance with the reduction in length of hospital stay observed in the corticosteroid group in these trials. By inhibiting cytokine production and endothelial activation, corticosteroids could impede the inflammatory cascade, reducing the need for exchange transfusion. The beneficial effects of corticosteroids is reported in other forms of vascular and lung injury. ${ }^{32}$

\section{Rebound effect and hospital readmission}

A risk of rebound pain was described in previous reports of corticosteroids in SCD..$^{18-24}$ This legitimate concern led physicians over the past years to restrict corticosteroids administration to hospitalized patients with SCD and Comorbid asthma. ${ }^{18,24}$ Despite the heterogeneous design of available studies, our pooled analysis showed that corticosteroids administered during VOC or ACS increased the risk for readmission within 72 hours to 2 weeks after hospital discharge. ${ }^{19-24}$ Interestingly, results from RCT and RCS are concordant for this outcome, with no interaction between subgroups. Several case reports described the poor tolerance of corticosteroids in SCD patients, with a high frequency of pain recurrence or relapse after withdrawal. ${ }^{33,34}$ One hypothesis could be a rebound upregulation of vascular cell adhesion molecule-1 on endothelium and delayed leukocytosis after corticosteroids withdrawal that can lead to VOC recurrence. ${ }^{5,35}$ Whether specific dose de-escalation protocols or adjuvant anti-inflammatory

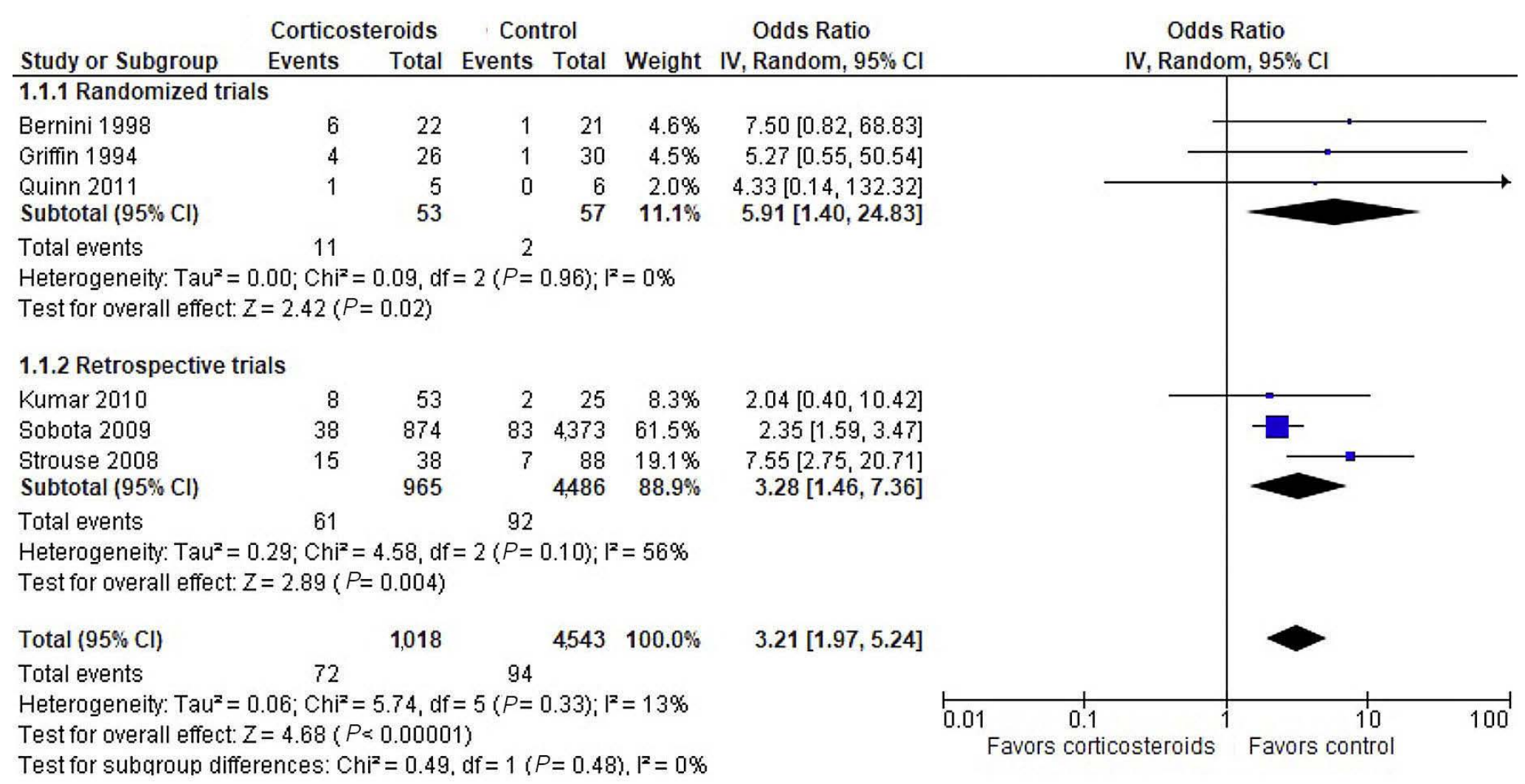

Figure 4. Effect of corticosteroid therapy on readmission rate. Cl: confidence interval. 
therapies might reduce the rebound upregulation induced by corticosteroids warrants further research.16,17 Exchange transfusion alters inflammation during SCD crisis, ${ }^{36}$ and its systematic association with corticosteroids might reduce the upregulation of inflammatory cascade observed after corticosteroids therapy withdrawal, ${ }^{5,35}$ and therefore the associated risk of rebound pain and readmission. Indeed, some authors observed a lack of rebound pain when dexamethasone was systematically associated with exchange transfusion in patients presenting severe $\mathrm{ACS}^{16}$ or mild VOC; ${ }^{17}$ the decrease of sickle red blood cell percentage, as a consequence of red cell exchange transfusion, might reduce the risk of rebound pain. Of note, three episodes of cerebral complication were reported in included studies (one stroke ${ }^{20}$ and two intracranial bleedings ${ }^{22}$ ), all in patients having received corticosteroids. The use of corticosteroids has already been associated with the occurrence of intracranial bleeding. ${ }^{37}$ Although the basis for this potential association remains unclear (e.g., increase of systolic blood pressure induced by corticosteroids might be poorly tolerated in SCD patients), physicians should consider this possible complication, notably in patients with other risk factors for intracranial bleeding. ${ }^{37}$

\section{Strengths and limitations}

We conducted a comprehensive and exhaustive literature search for comparative trials on corticosteroids use in the field of ACS or VOC. However, our study has several limitations. First, our systematic review found that trials assessing corticosteroids in the field of the two main acute complications of SCD are rare. Indeed, our research revealed only three RCT, with heterogeneous populations and intervention protocols, ${ }^{19-21}$ and three RCS with several inherent confounding bias. ${ }^{22-24}$ Second, results were divergent concerning the efficacy of corticosteroids, with steroids associated with reduced transfusion in RCT and more transfusions in RCS. However, we could scrutinize these conflicting results (subgroup interaction) and suggest a likely role for baseline severity in RCS. The association of steroid use with increased transfusions in RCS is complex to interpret because steroid use did not always precede transfusion in all patients, ${ }^{22}$ excluding a causal effect. Third, the populations and corticosteroids protocols were different among included studies: only one study assessed SCD patients presenting VOC ${ }^{19}$ and only one study assessed adult population. ${ }^{21}$ Nonetheless, our sensitivity analyses in patients with ACS and in the pediatric population were similar to those observed in the main analysis. Although they share some pathophysiological features, VOC and ACS are different primary diseases and these acute complications of SCD may have specific features in adult versus pediatric patients. Therefore, further studies are needed especially in patients with VOC and in the adult population. Fourth, we could not evalu- ate length of hospital stay in all included trials due to the lack of complete data in the retrospective cohorts. We nonetheless observed that corticosteroids reduced the length of hospital stay in RCT, along with reduced transfusion requirement. Last, we did not evaluate corticosteroid effects on the onset of pain crisis in patients free of VOC/ACS; indeed the demargination process induced by corticosteroids in non-hyperleukocytic patients could play a specific role. Similarly, although none of the included studies mentioned delayed hemolysis transfusion reaction, we cannot formally exclude an indication bias in patients with a medical history of delayed hemolysis transfusion reaction.

\section{Conclusion and future research}

In conclusion, as compared with standard care, corticosteroids administered to patients with VOC or ACS reduced the length of hospital stay and the need for transfusion in RCT but were associated with more transfusions in RCS. Corticosteroids increased the risk of readmission, both in RCT and RCS. Given the small number of included studies, the lack of data on volumes transfused, the presence of confounding bias in retrospective cohorts and the high heterogeneity of our analysis, we could not give any recommendation for the use of corticosteroids to treat VOC or ACS in patients with SCD.

Considering the potential benefit of corticosteroids, in particular in reducing the length of hospital stay, further prospective studies should be conducted. However, the risk of readmission associated with corticosteroids withdrawal must be carefully considered and anticipated when using corticosteroids in these trials.

\section{Disclosures}

No conflicts of interest to disclose.

\section{Contributions}

$J L, S G, E B$ and $A M D$ collected the data; JL, SG and AMD analyzed and interpreted the data; JL, SG and AMD drafted the manuscript; JL and AMD contributed to the study conception and design; $A M D, A H$ and $P B$ critically revised the manuscript. All authors read and approved the final manuscript.

\section{Acknowledgments}

We thank Timothy C. Griffin, author of one of the primary studies, who kindly provided supplementary information and data included in our systematic review and metaanalysis.

\section{Data-sharing statement}

The datasets and materials used and analyzed during the current study are available from the corresponding author on reasonable request. 


\section{References}

1. Ballas SK, Lusardi M. Hospital readmission for adult acute sickle cell painful episodes: frequency, etiology, and prognostic significance. Am J Hematol. 2005;79(1):17-25.

2. Booth C, Inusa B, Obaro SK. Infection in sickle cell disease: a review. Int J Infect Dis IJID Off Publ Int Soc Infect Dis. 2010;14(1):e2-e12.

3. Vichinsky EP, Neumayr LD, Earles AN, et al. Causes and outcomes of the acute chest syndrome in sickle cell disease. National Acute Chest Syndrome Study Group. N Engl J Med. 2000;342(25):1855-1865.

4. Kato GJ, Steinberg MH, Gladwin MT. Intravascular hemolysis and the pathophysiology of sickle cell disease. J Clin Invest. 2017;127(3):750-760.

5. Belcher JD, Mahaseth $\mathrm{H}$, Welch TE, et al. Critical role of endothelial cell activation in hypoxia-induced vasoocclusion in transgenic sickle mice. Am J Physiol-Heart Circ Physiol. 2005;288(6): $\mathrm{H} 2715-\mathrm{H} 2725$.

6. Okpala I. Leukocyte adhesion and the pathophysiology of sickle cell disease. Curr Opin Hematol. 2006;13(1):40-44.

7. Stuart MJ, Setty BN. Sickle cell acute chest syndrome: pathogenesis and rationale for treatment. Blood. 1999;94(5):1555-1560.

8. Moher D, Liberati A, Tetzlaff J, Altman DG, Group TP. Preferred reporting items for systematic reviews and meta-analyses: The PRISMA Statement. PLoS Med. 2009;6(7):e1000097.

9. Savović J, Weeks L, Sterne JAC, et al. Evaluation of the Cochrane Collaboration's tool for assessing the risk of bias in randomized trials: focus groups, online survey, proposed recommendations and their implementation. Syst Rev. 2014;3:37.

10. Page MJ, McKenzie JE, Higgins JPT. Tools for assessing risk of reporting biases in studies and syntheses of studies: a systematic review. BMJ Open. 2018;8(3):e019703.

11. Sterne JA, Hernán MA, Reeves BC, et al. ROBINS-I: a tool for assessing risk of bias in non-randomised studies of interventions. BMJ. 2016;355:i4919.

12. McGuinness LA, Higgins JPT. Risk-of-bias VISualization (robvis): An R package and Shiny web app for visualizing risk-of-bias assessments. Res Synth Methods. 2021;12(1):55-61.

13. Wan X, Wang W, Liu J, Tong T. Estimating the sample mean and standard deviation from the sample size, median, range and/or interquartile range. BMC Med Res Methodol. 2014;14:135.

14. Higgins JPT, Thompson SG. Quantifying heterogeneity in a meta-analysis. Stat Med. 2002;21(11):1539-1558.

15. Sedgwick P. Meta-analyses: heterogeneity and subgroup analysis. BMJ. 2013;346:f4040.

16. Isakoff MS, Lillo JA, Hagstrom JN. A single-institution experience with treatment of severe acute chest syndrome: lack of rebound pain with dexamethasone plus transfusion therapy. J Pediatr Hematol Oncol. 2008;30(4):322-325.

17. Yeral M, Boga C, Aytan P, Ozdogu H. Corticosteroid-induced vaso-occlusive events may be prevented by lowering hemoglobin $S$ levels in adults with sickle cell disease. Transfus Apher Sci. 2017;56(5):717-718.

18. Sobota A, Graham DA, Neufeld EJ, Heeney MM. Thirty-day readmission rates following hospitalization for pediatric sickle cell crisis at freestanding children's hospitals: Risk factors and hospital variation. Pediatr Blood Cancer. 2012;58(1):61-65.

19. Griffin TC, Mclntire D, Buchanan GR. High-dose intravenous methylprednisolone therapy for pain in children and adolescents with sickle cell disease. N Engl J Med.
1994;330(11):733-737.

20. Bernini JC, Rogers ZR, Sandler ES, Reisch JS, Quinn CT, Buchanan GR. Beneficial effect of intravenous dexamethasone in children with mild to moderately severe acute chest syndrome complicating sickle cell disease. Blood. 1998;92(9):3082-3089.

21. Quinn CT, Stuart MJ, Kesler K, et al. Tapered oral dexamethasone for the acute chest syndrome of sickle cell disease: Short Report. Br J Haematol. 2011;155(2):263-267.

22. Strouse JJ, Takemoto CM, Keefer JR, Kato GJ, Casella JF. Corticosteroids and increased risk of readmission after acute chest syndrome in children with sickle cell disease: acute chest syndrome in sickle cell disease. Pediatr Blood Cancer. 2008;50(5):1006-1012.

23. Kumar R, Qureshi S, Mohanty P, Rao SP, Miller ST. A short course of prednisone in the management of acute chest syndrome of sickle cell disease. J Pediatr Hematol Oncol. 2010;32(3):e91-94.

24. Sobota A, Graham DA, Heeney MM, Neufeld EJ. Corticosteroids for acute chest syndrome in children with sickle cell disease: variation in use and association with length of stay and readmission. Am J Hematol. 2010;85(1):24-28.

25. Habibi A, Arlet J-B, Stankovic K, et al. [French guidelines for the management of adult sickle cell disease: 2015 update]. Rev Med Interne. 2015;36(5 Suppl 1):5S3-84.

26. Cooper TE, Hambleton IR, Ballas SK, Johnston BA, Wiffen PJ. Pharmacological interventions for painful sickle cell vasoocclusive crises in adults. Cochrane Database Syst Rev. 2019;2019(11):CD012187.

27. Dunlop RJ, Bennett KCLB. Pain management for sickle cell disease. Cochrane Database Syst Rev. 2006;(2):CD003350.

28. Meremikwu MM, Okomo U. Sickle cell disease. BMJ Clin Evid. 2016;2016:2402.

29. Dolatkhah R, Dastgiri S. Blood transfusions for treating acute chest syndrome in people with sickle cell disease. Cochrane Database Syst Rev. 2020;1(1):CD007843.

30. Ogunlesi F, Heeney MM, Koumbourlis AC. Systemic corticosteroids in acute chest syndrome: friend or foe? Paediatr Respir Rev. 2014;15(1):24-27.

31. Vandy Black L, Smith WR. Evidence-based mini-review: are systemic corticosteroids an effective treatment for acute pain in sickle cell disease? Hematol Am Soc Hematol Educ Program. 2010;2010(1):416-417.

32. RECOVERY Collaborative Group, Horby P, Lim WS, et al. Dexamethasone in hospitalized patients with Covid-19 preliminary report. N Engl J Med. 2021;384(8):693-704.

33. Couillard S, Benkerrou M, Girot R, Brousse V, Ferster A, BaderMeunier B. Steroid treatment in children with sickle-cell disease. Haematologica. 2007;92(3):425-426.

34. Darbari DS, Fasano R s., Minniti CP, et al. Severe Vaso-occlusive episodes associated with use of systemic corticosteroids in patients with sickle cell disease. J Natl Med Assoc. 2008;100(8):948-951.

35. Mishler JM, Emerson PM. Development of neutrophilia by serially increasing doses of dexamethasone. $\mathrm{Br} \mathrm{J}$ Haematol. 1977;36(2):249-257.

36. Liem RI, O'Gorman MR, Brown DL. Effect of red cell exchange transfusion on plasma levels of inflammatory mediators in sickle cell patients with acute chest syndrome. Am J Hematol. 2004;76(1):19-25.

37. Strouse JJ, Hulbert ML, DeBaun MR, Jordan LC, Casella JF. Primary hemorrhagic stroke in children with sickle cell disease is associated with recent transfusion and use of corticosteroids. Pediatrics. 2006;118(5):1916-1924. 